\title{
ARE RETURNS TO Private Infrastructure In DeVeloping COUNTRIES CONSISTENT WITH RISKS SINCE THE ASIAN CRISIS?*
}

\author{
Antonio Estache \\ (The World Bank and ECARES, Universite Libre de Bruxelles) \\ Maria Elena Pinglo \\ (The World Bank)
}

\begin{abstract}
This paper presents a basic assessment of the financial performance of infrastructure service operators in developing countries. It relies on a new database of 120 companies put together to track the evolution of the cost of capital, the cost of equity and the return to equity for electricity, water and sanitation, railways and port operators in 31 developing countries distributed evenly across low-income, low-middle income and uppermiddle-income countries. The paper shows that between 1998 and 2002, the average cost of capital in developing countries varied from less than $11 \%$ to over $15 \%$ across regions and sectors while the cost of equity varied from around $13 \%$ to over $22 \%$. Low-middle-income countries have recovered relatively well from the East Asia crisis, while low-income and upper-middle-income countries have seen their situation deteriorate since the crisis. At the regional level, the main story is that East Asia is recovering quite well from its crisis, and that the financial performance of the operators in Africa and Latin America has deteriorated. Eastern Europe and South Asia are doing relatively better but show a large volatility of returns over time and within sectors. At the sector level, the railways and the energy sectors have seen their performance deteriorate significantly over the period, while the water and port sectors have done relatively better. In all sectors and regions, the average return to equity has been lower than the cost of equity since the Asian crisis.
\end{abstract}

\section{World Bank Policy Research Working Paper 3373, August 2004}

The Policy Research Working Paper Series disseminates the findings of work in progress to encourage the exchange of ideas about development issues. An objective of the series is to get the findings out quickly, even if the presentations are less than fully polished. The papers carry the names of the authors and should be cited accordingly. The findings, interpretations, and conclusions expressed in this paper are entirely those of the authors. They do not necessarily represent the view of the World Bank, its Executive Directors, or the countries they represent. Policy Research Working Papers are available online at http://econ.worldbank.org.

* This paper was prepared as a background note to a forthcoming report to be published by the World Bank Infrastructure Vice-Presidency on the State of Infrastructure in the Developing World. We are grateful to Ian Alexander, Cecilia Briceno, Phil Burns, Claude Crampes, Luis Correia, Severine Dinghem, Ana Goicoechea, Andres Gomez-Lobo, Emili Grifell, Jose-Luis Guasch, Malick Gueye, Martin Rodriguez-Pardina, Richard Schlirf, Sophie Sirtaine, Moctar Touré, Lee Travers and Lourdes Trujillo as well as to the participants in WBI seminars for infrastructure regulators in Berlin, Dakar and Paris, to the participants in seminars at AFD, GTZ and the OECD and to those at more academic seminars at the Universite de Paris I and the Berlin University of Technology for useful discussions and/or comments. 


\section{Introduction ${ }^{1}$}

During the 1990s, private sector commitments to infrastructure projects in developing countries amounted to about US\$805 billion, or about US\$67 billion/year. Private sector investment represented about $20-25 \%$ of the investment expenditures of these countries during that period. This average figure hides the strong fluctuations caused by increased global financial instability. Indeed, commitments increased sharply up to 1997, when they started to decline rapidly after the Asia crises was followed by similar crisis in Russia, Brazil and more recently Argentina. In 2002, commitments totaled US $\$ 46.7$ billion, the lowest level of investment since 1994.

It is now almost a panecea to state that the significant slow down in private investments in infrastructure is simply the reaction to unacceptable levels of risk from the point of view of potential infrastructure service operators. There is a sense that projects do not generate the cash flows needed to at least operate and maintain infrastructure. There is also a clear concern that exchange rate risk levels have become increasingly incompatible with the fact that the cash flows for many of the services are generated in local currency, while investors and borrowers want dividends and debt service in hard currency.

The decline in private sector commitments has fueled the debate on the realism of the expectation to have the private sector contribute to the infrastructure financing needs of the developing countries. Some observers are convinced that this is only a temporary slowdown and that the private sector will return. Many others are more skeptical not only about the return of private investors, but in some cases also the desirability of this return. The odds are, however, that the private sector will eventually return, at least in the high-potential countries. This is simply because these countries represent large markets with significant potential returns on investment in the long run. But public-private partnerships will also survive the current crisis because few developing countries will be able to address their extraordinary infrastructure needs from public resources alone. ${ }^{2}$ Ultimately, the disagreement should probably be as to how fast the private sector will return to some countries and under what conditions.

When the private sector returns in larger numbers, it will indeed do so in very different forms from those we have observed in the 1990s. Their willingness to accept risk will be limited. This will require new contractual arrangements with different levels and types of risksharing arrangements. It will also imply new actors, including non-OECD (Organization for economic cooperation and development) actors willing to compete in risky environments they are more familiar with than OECD operators - e.g. South African infrastructure firms are increasingly present throughout Africa, Malaysian firms in Asia and Africa, Brazilian and Mexican firms throughout Latin America.

The new business models also demand better governance in business practices. An improvement in the accountability of all stakeholders in public-private partnerships will require much more transparency in the analytical and quantitative assessments of deals. These

\footnotetext{
${ }^{1}$ This paper extends to all developing countries of part of a database put together for Latin America by Sirtaine et al. (2004) for Latin America but covers a much shorter period and a lower number of return indicators.

${ }^{2}$ For the poorest countries unable to attract private investment, the alternative is likely to be grants from richer countries.
} 
assessments are needed to facilitate debates between governments and operators on the specific levels of risks associated with any project and on their distribution. This debate has already started in Argentina, Brazil, Kenya, Mali, Mexico or Uganda where electricity, ports or water operators and regulators or governments are arguing about quantitative estimates of the rate of return required by operators to match the demands of their equity and bond holders.

This paper's main goal is to provide a quantitative baseline of the risks perceived between 1998 and 2002 by private providers for a range of infrastructure services in a range of developing countries based on a sample of 120 companies. We do so by calculating the hurdle rates for each one of these operations (that is, the risk-adjusted cost of capital faced by the operators). The data available do not allow the assessment of the financial viability of these operations but allow a comparison of the returns on equity with the cost of equity for the same sample. This comparison is used to highlight the origin of the concerns of private investors.

The paper is organized as follows. In section 2, we present the methodology and the data. Section 3 presents the estimates of the cost of capital. Section 4 compares the cost of equity to the return on equity to get a sense of the returns that are consistent with the risks perceived by investors in infrastructure. Section 5 presents the results on the cost of capital, and section 6 on the comparison between the cost of equity and the return on equity. Section 7 privides some insights on the volatility of returns and costs. Section 8 reviews the evolution of the indicators over time. Section 9 concludes.

\section{The Sample of Companies}

We focused on companies active in four infrastructure sectors: energy, water, ports and railways. We only used publicly available information on the Web. Indeed, various commercial databases and a Web search provided us with the balance sheets, financial statements and related information for 120 companies. The information was checked whenever possible either on the site of the companies or on the sites of their regulators in the countries in which they are operating. We also relied on reports generated by credit rating agencies or investment banks to cross reference the information. The sample covers 31 developing countries in five regions: Sub-Saharan Africa \& MENA (11), South Asia (12), East Asia (30), Europe \& Central Asia (12), Latin America and the Caribbean (55). Latin America and East Asia provide, as expected, the largest number of companies since these are the two regions which generate over $75 \%$ of public-private partnerships over the $1990 \mathrm{~s}$. The distribution of the sample per income groups or geographical regions, per sector is summarized in Table 1.

The table points clearly to the limited statistical significance of the sectoral observations for the water, port and rail sample in Africa, South Asia and Eastern Europe. Classifications by country income group (low-income, lower-middle-income, upper-middle-income) were less problematic because they take all countries with the same average risk level and compare them with appropriate hurdle rates, which have the same average risk level as well. The sample size for the low income group is however also limited for all sectors, except energy. 
Table 1: The sample of concessions used

\begin{tabular}{|l|c|c|c|c|c|c|}
\hline & Total by Country & Total by company & \multicolumn{4}{|c|}{ Total By Sector } \\
\cline { 2 - 7 } & & & Energy & Water & Port & Rail \\
\hline Low income & 9 & 18 & 12 & 2 & 2 & 2 \\
Lower middle income & 11 & 38 & 16 & 8 & 11 & 3 \\
Upper middle income & 11 & 64 & 20 & 14 & 19 & 11 \\
\hline Total & $\mathbf{3 1}$ & $\mathbf{1 2 0}$ & $\mathbf{4 8}$ & $\mathbf{2 4}$ & $\mathbf{3 2}$ & $\mathbf{1 6}$ \\
\hline Sub-Saharan Africa \& Mena & 9 & 11 & 7 & 3 & 1 & 0 \\
South Asia & 3 & 11 & 7 & 0 & 2 & 2 \\
East Asia \& Pacific & 4 & 31 & 12 & 5 & 11 & 3 \\
Europe and Central Asia & 6 & 12 & 7 & 0 & 3 & 2 \\
Latin America and Caribbean & 9 & 55 & 15 & 16 & 15 & 9 \\
\hline Total & $\mathbf{3 1}$ & $\mathbf{1 2 0}$ & $\mathbf{4 8}$ & $\mathbf{2 4}$ & $\mathbf{3 2}$ & $\mathbf{1 6}$ \\
\hline
\end{tabular}

The actual sample we collected was somewhat larger in the hope to have enough coverage of every region and sector but we also imposed a number of restrictions to maintain a minimum level of quality in the sample. To be included in our sample, a company had to have a minimum of at least 5 years of operations (in order to have a time series of data of adequate duration for the analysis). Moreover, only audited financial statements and official company information releases were used.

We have four major potential problems with our data sample which need to be taken into account when analyzing the results. First, because companies must obey the accounting standards of the countries where they operate, they may follow different accounting rules when preparing their financial statements. Although accounting standards in all the countries considered are based on international accounting standards (IAS), discrepancies across countries may generate differences in earnings. No attempt was made to adjust financial statements for possible differences in accounting standards.

Second, no matter where they operate, companies generally do not publish certain data that would have been helpful for the analysis. This includes, for example, information on the fair value of some assets, depreciation and amortization rules, and detailed classification of costs. It also applies to the market value of assets and liabilities, so the analysis is based on their book value.

Third, some analysts argue that regulations sometimes create incentives for investors to present their accounts in a way that shows the lowest possible return or profitability. This can happen, for example, when regulated tariffs are set to ensure a minimum return to concessionaires - encouraging them to minimize their historical returns in order to maximize future tariff increases. Since different countries and different sectors follow different regulatory regimes, this may be additional source of distortion. We did not take this one into account either. ${ }^{3}$

Fourth, the financial results of infrastructure concessions are usually sensitive to their life cycles. It is not uncommon to incur losses in the early years, when processes are being adjusted and heavy investments are often made. By contrast, profitability usually increases in

\footnotetext{
${ }^{3}$ See for instance Alexander et al (2001) for illustrations of the relevance of the regulatory regime for the assessment of the cost of capital
} 
later years as systems become more efficient. Thus comparing companies at different stages of their life cycles is not ideal. Accordingly, no attempt is made to compare data for individual concessions, because doing so might not be meaningful. But this problem is not as severe when calculating averages for the entire sample, because the sample contains concessions at most stages of their life cycles

\section{The Methodology and the basic data}

Since the initial purpose of the paper is to get a sense of the recent evolution in the risk levels faced by operators, it is essential to be able to quantify these risks in a systematic manner across regions, across sector and over time. These risks are best assessed by estimating what drives the rates of return demanded by these companies from governments in developing countries. These demands are driven the main sources of risks types and levels perceived by the shareholders and the lenders to private operators in developing countries and lead to what amounts to a hurdle for the projects. This is why the first stage of the methodology followed in this paper is to assess this hurdle rate.

For regulated industries as those covered in this paper, a standard way to assess quantitatively this rate is to estimate the cost of capital faced by the operators on a specific project. The weighted average cost of capital (WACC) is the expected return on all of a company's securities. It is measured as the average return required on each source of capital-such as stock, bonds, and other debts-weighted by the share of each in the company's financing structure. The calculation is often simplified by grouping the various sources of capital into just two categories: equity and fixed income or debt instruments. It is the appropriate hurdle rate for measures of returns on a project's overall liabilities. Formally, WACC is estimated by:

$$
W A C C=\left[(1-g) * C_{e}\right]+\left[g *(1-T) * C_{d}\right]
$$

where:

$g$ is the level of leverage (or gearing in the UK) in a company, i.e. the proportion of debt in the total capital structure (i.e. debt + equity or $\mathrm{D}+\mathrm{E}$ where $E$ is the book value of equity and $D$ is long-term debt);

$C_{d}$ is the cost of debt finance. This is simply measured as risk free rate, $r_{f}$ plus a debt premium over this rate, $\mathrm{p}_{d}$.

$C_{e}$ is the cost of equity finance; it is a measure of the return investors require on equity investments, given the level of risk of such investments; its estimation raises bigger problems and yet for privatized infrastructure monopolies, it is quite important since access to debt finance can be quite restricted for many developing countries privatization projects.

$T$ is the nominal corporate income tax rate.

In a developing country context, the assessment of each one of these components is quite challenging. The most difficult task, however, ended up being the estimation of the cost 
of equity. One of the common approaches adopted to measuring the cost of equity is the Capital Asset Pricing Model (CAPM). ${ }^{4}$ The estimate the cost of equity follows formula (2):

$$
\mathrm{C}_{\mathrm{E}}=\mathrm{r}_{\mathrm{f}}+\beta_{\mathrm{e}} *\left(\mathrm{r}_{\mathrm{m}}-\mathrm{r}_{\mathrm{f}}\right)+\mathrm{Crp}
$$

where: $\quad r_{\mathrm{f}}=$ risk free rate

$\beta_{\mathrm{e}}=$ the equity beta of the project

$\mathrm{r}_{\mathrm{m}}=$ expected stock market return

Crp $=$ country risk premium

The risk-free rate of return $\left(\boldsymbol{r}_{\boldsymbol{f}}\right)$ is a benchmark figure against which all investments in an economy should be measured. Being risk-free requires the removal, or minimization, of repayment risk. Owing to the ability of a government to raise finance through taxation, government bonds are normally taken as the base value for the calculation. But sometimes governments in emerging or developing markets have failed to meet their financial obligations - and thus are clearly not risk-free. As a result the interest rate on U.S. threemonth Treasury bills is usually considered the best approximation of a risk-free rate. Here the risk-free rate is calculated using the geometric average of the average annual interest rate on U.S. three-month Treasury bonds over a 40-year period (from 1962-2002). This average produces a risk-free rate of 6.96 percent. Table A1, in the appendix, contains the data used in the calculation. Annual averages were used because all of our measures of returns are annual. A 40-year timeframe was used because it is broadly consistent with the average duration of the infrastructure concessions and because it is long enough not to be distorted by short-term economic circumstances. Finally, a geometric average was used (instead of an arithmetic average) because empirical evidence suggests that, over a long period, returns become serially correlated.

The market risk premium $\left(r_{m}-r_{f}\right)$ relates to the level of additional return that is required to persuade investors to hold equities in preference to the risk free instrument. There is much controversy surrounding the calculation of this element-recent UK regulatory experience has generated figures between $3 \%$ and $6 \%$ while some parts of traditional finance theory suggests orders of magnitude of at most $2 \%$. An alternative is to measure the historical spread between the yield on a government security and that of a general market index--in the US, this could be the spread between the yield on a 1 year Treasury Bill and the returns on the 500 Standard \& Poor index. We used the geometric average of these excess returns over $1962-2002$, and obtained a market risk premium of 2.94 percent. ${ }^{5}$

\footnotetext{
4 Note that the CAPM approach has often been criticized for a number of conceptual reasons including a number of assumptions made on the efficiency of the markets. Some of the criticisms are particularly relevant for developing countries where capital markets are typically even less perfect than in developed countries. There is, however, no unanimous agreement on any other model for now and the CAPM continues to be the approach underlying most tariff revisions in developing countries as well as in developed countries. For a recent survey of practice, see Alexander (2004). Note that he observation that expected returns are related to risk through the CAPM was first formalized by Jack Trenor, William Sharpe (1964), and John Lintner (1965).

${ }^{5}$ The average returns on stocks between 1962 and 2002 was $9.9 \%$ while the yield on the US Tbill was $9.96 \%$. The difference gives the market risk premium of $2.94 \%$.
} 
The equity beta $\left(\beta_{e}\right)$ measures the relative risk of the company's equity compared to the market as a whole. In other words, the risk premium investors require for taking on a riskier investment varies in direct proportion to its beta. Betas are estimated regularly by numerous specialized private companies. Some companies use a simple covariance method, based on historical stock prices, to get a historical beta. ${ }^{6}$ Although some studies have shown that betas appear reasonably stable (see Sharpe and Cooper 1972), historical betas are imperfect guides to the future because a stock's market risk can change considerably. Accordingly, some other companies, such as Barra, ${ }^{7}$ use more forward-looking methodologies - adjusting historical betas to take into account forward-looking quantitative and qualitative information about the stock and its environment (including the regulatory framework). The results, called predicted or fundamental betas, are considered superior to historical betas because they incorporate new information that may influence the stock's future volatility. Thus they are better predictors of an asset's future response to market movements which is why we used them here. But companies such as Barra do not calculate betas for nontraded companies or for small companies with limited liquidity, especially in emerging markets. Therefore, one must use proxies. We proxied the betas of our sample concessions using the average predicted betas estimated by Barra for U.S. companies operating in the same sectors. ${ }^{8}$ The resulting betas are summarized in Table 2. The average betas are less than 1 for all the infrastructure sectors considered in this paper analysis. That means that stocks of companies in those sectors are usually less volatile than the market, so investments in those sectors are less risky than in sectors with higher betas. This reflects the fact that these sectors enjoy more stable economics - particularly more stable demand - than do other sectors.

Table 2: Sector Specific Betas

\begin{tabular}{|l|c|c|c|c|c|}
\hline $\begin{array}{l}\text { Average } \\
\text { Unleveraged Betas }\end{array}$ & $\mathbf{1 9 9 8}$ & $\mathbf{1 9 9 9}$ & $\mathbf{2 0 0 0}$ & $\mathbf{2 0 0 1}$ & $\mathbf{2 0 0 2}$ \\
\hline Electricity & 0.46 & 0.36 & 0.36 & 0.31 & 0.36 \\
\hline Water \& Sanitation & 0.42 & 0.36 & 0.51 & 0.34 & 0.31 \\
\hline Railroad & 0.82 & 0.66 & 0.53 & 0.53 & 0.55 \\
\hline Ports & 0.41 & 0.41 & 0.41 & 0.41 & 0.41 \\
\hline
\end{tabular}

Source:Barra betas by sector

Note: For ports, we used the betas for maritime transport

To isolate the risks resulting from a company's financing structure from its fundamental business risk, betas are usually calculated assuming that the company has a

\footnotetext{
6 A stock's relative volatility is measured as the ratio of the covariance between the stock's and the market's return divided by the variance of the market's return.

${ }^{7}$ Barra, a U.S. company founded in 1975, became famous for its multifactor model for measuring the risk of stock portfolios. Its estimates of betas are used by many investment banks and stock brokers.

${ }^{8}$ European companies were used when Barra's data for U.S. companies were insufficient. For instance, Barra's data do not separate U.S. energy distributors and generators. So, its data for European energy companies were used.
} 
hypothetical unleveraged financial structure. (They are then called unleveraged or unlevered betas.) All the betas in Table 2 are unleveraged. To account for the extra risk embedded in companies' leveraged capital structure (making them leveraged or levered betas), they must be releveraged using the formula (3):

$$
\beta_{\mathrm{L}}=\beta_{\mathrm{U}} *[1+\mathrm{D} / \mathrm{E} *(1-\mathrm{T})],
$$

where $\beta_{L}$ is the leveraged beta, $\beta_{U}$ is the unleveraged beta, $D$ is outstanding long-term debt, $E$ is total equity, and $T$ is the corporate income tax rate. In this analysis, unleveraged betas were transformed into leveraged betas using a capital structure typical for each sector estimated as the average leverage of our sample companies which are summarized in Table 3.

Table 3: Average leverage by sector

\begin{tabular}{|l|c|c|c|c|c|}
\hline & $\mathbf{1 9 9 8}$ & $\mathbf{1 9 9 9}$ & $\mathbf{2 0 0 0}$ & $\mathbf{2 0 0 1}$ & $\mathbf{2 0 0 2}$ \\
\hline Electricity & $87 \%$ & $87 \%$ & $87 \%$ & $86 \%$ & $97 \%$ \\
\hline Water \& Sanitation & $103 \%$ & $112 \%$ & $83 \%$ & $79 \%$ & $145 \%$ \\
\hline Railroad & $43 \%$ & $45 \%$ & $46 \%$ & $50 \%$ & $76 \%$ \\
\hline Ports & $104 \%$ & $93 \%$ & $106 \%$ & $122 \%$ & $90 \%$ \\
\hline
\end{tabular}

Source: own calculations based on sample data

The country risk premium (Crp) is the extra return that investors require to invest in stocks of companies in a country deemed riskier than a less risky country used as benchmark (often the United States). The premium reflects the potential volatility of investments in a given country due to defaults associated with political or other events. Country risk premiums are usually estimated as the average spread over U.S. Treasury bonds (assumed to be riskfree) of U.S. corporate bonds with a credit rating equivalent to that of the country under consideration (called the default spread). To estimate these spreads, we used default spreads estimated by Reuters for a large number of utilities worldwide. ${ }^{9}$ However, Reuters does not calculate this default spread for a number of developing countries such as, but not limited to Mozambique, Cameroon, Georgia and Estonia. As a result, for these countries, we utilized Fitch, Standard \& Poor or Moody's ratings where available and then, proxied these default spreads using rating equivalences published by Moody's.

The country risk premium is the most discriminating factor among countries, ranging from less than 1 percent in Chile and South Africa to 13-15 percent in Argentina, Kenya and Venezuela. It is also highly volatile - varying, for example, from 8 percent in 1998 to 13 percent in 2002 in Argentina. This is because it is influenced by many factors subject to frequent shocks and variations, including exchange rate risk, political risk, and regulation risk. It is for this reason that one needs to make sure the calculation compares investors' expected

\footnotetext{
${ }^{9}$ Some authors argue that the country risk premium is likely to be higher than the country's default spread. Instead, they multiply the default spread by the ratio of the volatility of the equity market to that of the bond market in the country under consideration (sometimes proxied by the same ratio globally of 1.5). To be as conservative as possible, we have not made such an adjustment
} 
returns at any point in time with the cost of equity at the same time. Figure 1 gives a sense of the extent to which the hurdle rates can differ across regions simply as a result of this country risk premium

Figure 1: Evolution of country risk premiums over time (1998-2002)
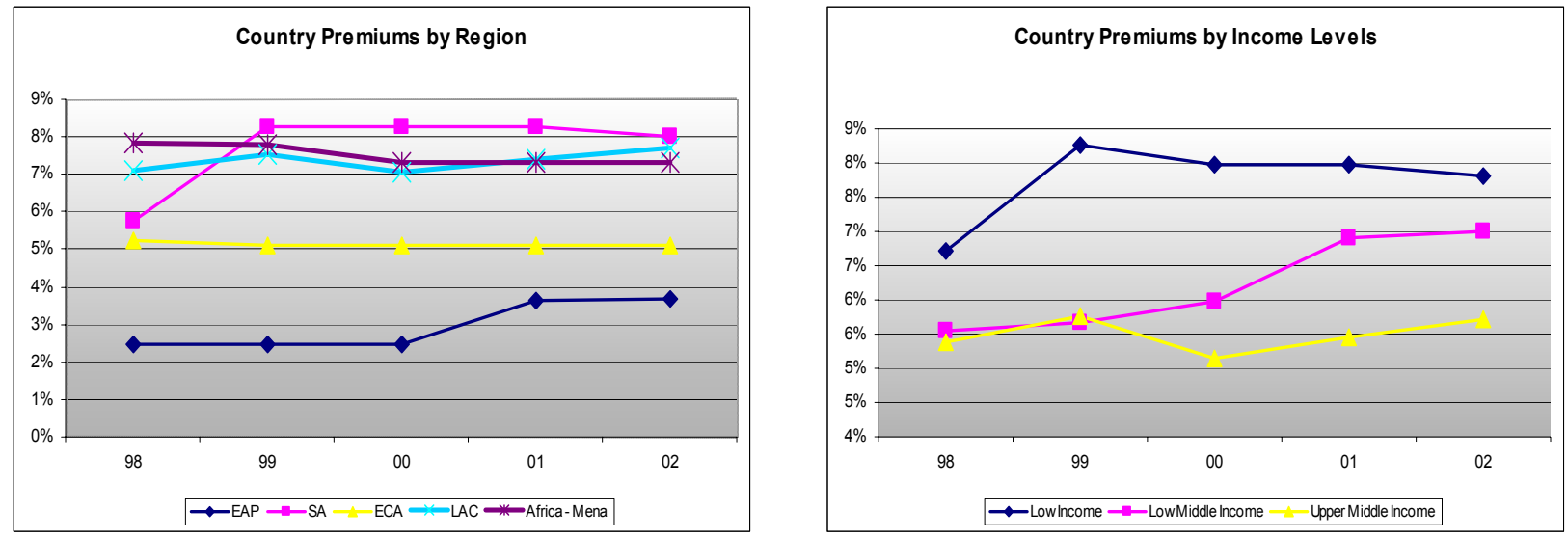

Source: Own calculation based on data from Moody's and Bondsonline.

The cost of debt is measured by formula (4)

$$
C_{d}=(\mathrm{Rf}+\mathrm{Cbp}+\mathrm{Crp}) *(1-\mathrm{T})
$$

Where: $\quad$ rf $=$ Risk free rate

$\mathrm{Cbp}=$ Premium for corporate issues

Crp = Country risk premium

$\mathrm{T}=$ Average effective corporate income tax rate

We used a typical cost of debt for each country. However, we did not estimate the cost of debt and its changes resulting from debt renegotiations or restructuring. ${ }^{10}$ The risk free rate and the country risk premium are estimated as explained earlier. The tax rate is from the Price- Waterhouse assessment of the effective corporate income tax rate levied on a medium to large size company (defined in terms of sales amount). The rates used are provided in Appendix Table A2. The Premium for corporate issues is estimated at 20bp premium over sovereign issues. ${ }^{11}$ Note also that we did not try to estimate the cost of potential debt renegotiation / restructuring.

\footnotetext{
${ }^{10}$ This means that we are probably underestimating the effective cost of debt since in developing countries debt structures for infrastructure projects are usually much shorter than in developed economies and the transaction costs (including numerous fees) associated with the need to regularly restructure or relaunch the debt can be quite large and should ideally be added to the nomimal interest rate. But this information is largely viewed by bankers to be a commercial secret and can unfortunately not be reflected in the data used here.

${ }_{11}$ Note that we used the same country risk premium (a historical country risk premium) as we did to compute the cost of equity. The country risk premium relevant to compute the cost of debt may however be different since the relevant horizon is usually shorter (it would be higher if the risk of investing in a given country is perceived as higher in the short term than in the long term, and vice a versa).
} 
Once the hurdle rates has been estimated, i.e. the cost of capital and its components including the cost of equity, it is useful to try to generate estimates of the rates of returns on assets and on equity to get a sense of the extent to which risks are consistent with the returns earned. To do so we rely on accounting data to measure each company's overall return on the capital invested in each infrastructure project since $1998 .^{12}$

In theory, several measures of the effective returns earned by the operators can be used such as the return on assets, the internal rate of return or the return on equity. The first two measures can however not be estimated due to data problems. We have to rely instead on the return on equity (RoE) which is the least complete indicator of the three. The return on equity (RoE) is a measure of the after tax return the company is earning on its equity capital. It reflects the profits a company is able to generate given the resources provided by its shareholders. It is the ratio of the project's net income divided by the shareholders' equity investment in the project and can be expressed as:

$$
\text { RoE }=\text { Net income / Shareholders' equity }
$$

where:

$$
\begin{gathered}
\text { Shareholders' equity }=\text { total assets minus total liabilities; } \\
\text { and, } \\
\text { Net income }=\text { after-tax profit }
\end{gathered}
$$

The main problem with this measure is that it is unclear whether it underestimates or overestimates the returns of a business. First, in the short run, it tends to overestimate returns because it assumes that all the income generated by a project represents compensation for shareholders. Indeed, at least in the early years of a project, investors receive only a portion of a project's net income. The rest is reinvested in the company and produces income for investors only when the company is sold or transferred back to the government-provided that transaction occurs at a market price higher than the initial investment and shareholders are compensated for the value they created by reinvesting what otherwise would have been compensation. Thus the estimates reported here should be seen as a ceiling on shareholders' potential returns in the short to medium run at least. Second, it is the victim of more subtle accounting conventions which tend to underestimate the actual returns of these infrastructure operations in developing countries. The best known source of underestimation is the fact that many infrastructure operators enjoy implicit or explicit management contracts, in addition to the concession or license to provide a service. These management contracts tend to give rise to fees paid to the headquarters but which appear as cost in the financial accounting of the local companies. These fees provide in fact a lower bound for the return to the operation.

With the limitations pointed out throughout this section, the RoE is likely to be an upper bound of the return on equity-ignoring the return generated by the management fee. In our analysis, we thus compare the RoE of each company to the corresponding Cost of equity, $\left(C_{E}\right)$. When the $R o E$ is higher than the appropriate $C_{E}$, returns are higher than alternative of

\footnotetext{
12 Due to data limitations and because many of the companies in the sample are non-traded companies, the study utilizes book values (in the weighting of cost of capital) instead of market values. As an unintended, and potentially misleading consequence, the resulting WACC may be understated. Conversely, if book values are higher than market values, WACC may be erroneously inflated.
} 
similar risk. When the $\mathrm{RoE}$ is lower than the appropriate $\mathrm{C}_{\mathrm{E}}$, returns are lower than alternative of similar risk and the operators will pull out or not consider further expansions or projects.

\section{Estimates of the hurdle rates}

The comparison of the cost of capital (WACC)) estimated across regions and country groups provides a good sense of the relative competitiveness of these sectors and regions in attracting private sector investment in infrastructure. We report only the average over the 1998-2002 period since it provides the best sense of the perception of the minimum required returns by potential investors. It is thus taken to be a fair indicators of expectations.

Figure 2 aggregates the data per developing countries classified according to income group levels (low income (LIC), low middle income (LMC) and upper middle income (UMC)), ignoring the sectoral differences. ${ }^{13}$ The results are as expected, the highest average demanded returns $(14.9 \%)$ are in the lowest income countries and the lowest demanded returns are in the highest income countries (around 10\%). This is quite consistent with the fact that higher perceived risks are expected to yield higher expected returns. More specifically, between 1998 and 2002, investors seeking to invest in low income level countries required on average, returns around $15 \%$ in order to find investments in such countries attractive. The same graph shows that investors seeking to invest in countries defined by low-middle income levels will require returns around $11 \%$ which is not very significantly higher than the expectations for upper middle income countries.

Figure 2: Estimated weighted average cost of capital by income distribution levels_(1998-2002)

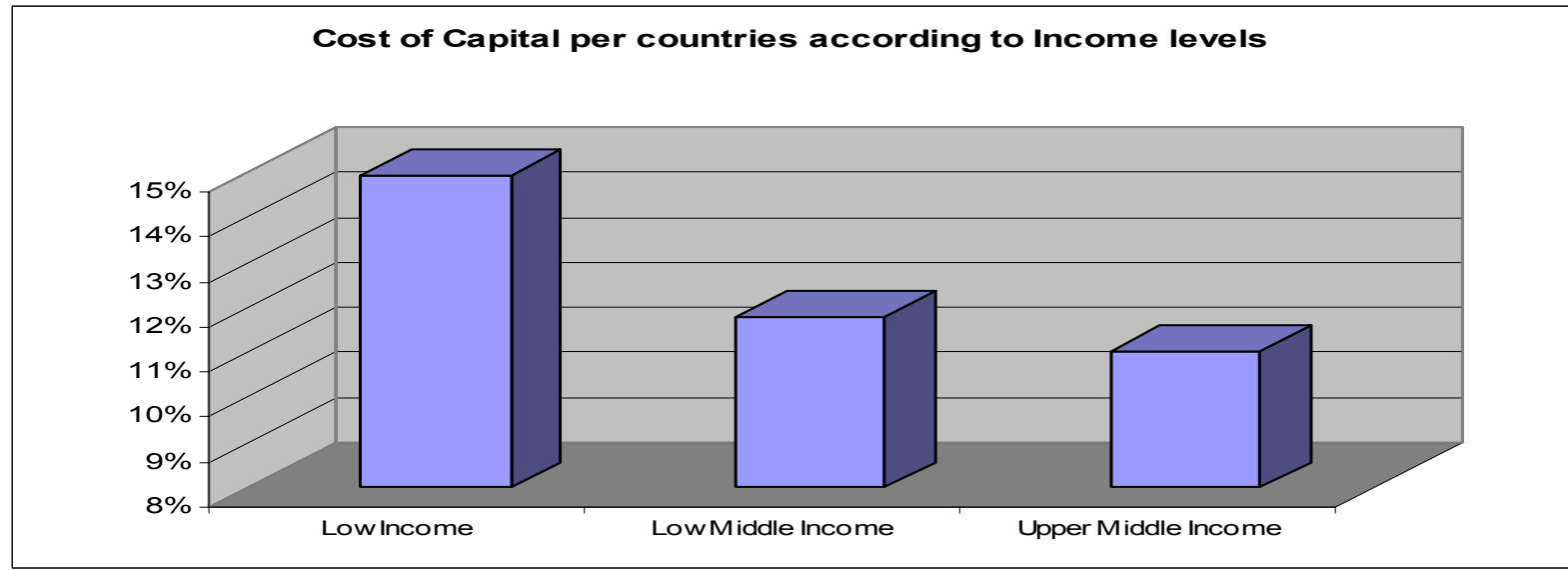

The second aggregation of the data presented is per region, still ignoring sectoral differences for now. The results are summarized in Figure 3. The cost of capital varies from about $9 \%$ to almost $15 \%$ under the assumptions we made, most importantly on the cost of

\footnotetext{
13 This corresponds to the standard World Bank classification. The specific definitions are as follows: Low-income economies are those in which 2001 GNI per capita was US\$745 or less; low middle-income are those with 2001 GNI per capita was between US\$745 and US\$2,975 and upper-middle-income economies have a 2001 GNI per capita was between US\$2,976 and US\$9,205.
} 
debt and the leverage rates. The results are somewhat surprising in that they imply that East Asia (with a cost of capital of $8.6 \%$ ) is the region that has best recovered from ... the East Asia crisis. Among all regions, the return required were the lowest in East Asia and the highest in Africa (Sub-Saharan Africa + the Middle East) and South Asia. Demands in Eastern Europe are quite high. The results reflect quite clearly the importance of the risk perceptions of the potential investors in the sector right after the 1997 crisis. For many credit rating agencies, Latin America was expected to follow East Asia's fall. As for the poorest regions of the world, the sense of risk has always been high and these results do not represent significant changes over past experiences. Recent tariff revisions in electricity in Kenya and Mali have in fact pointed to cost of capital figures over $20 \%$.

Figure 3: Estimated weighted average cost of capital by region(1998-2002)

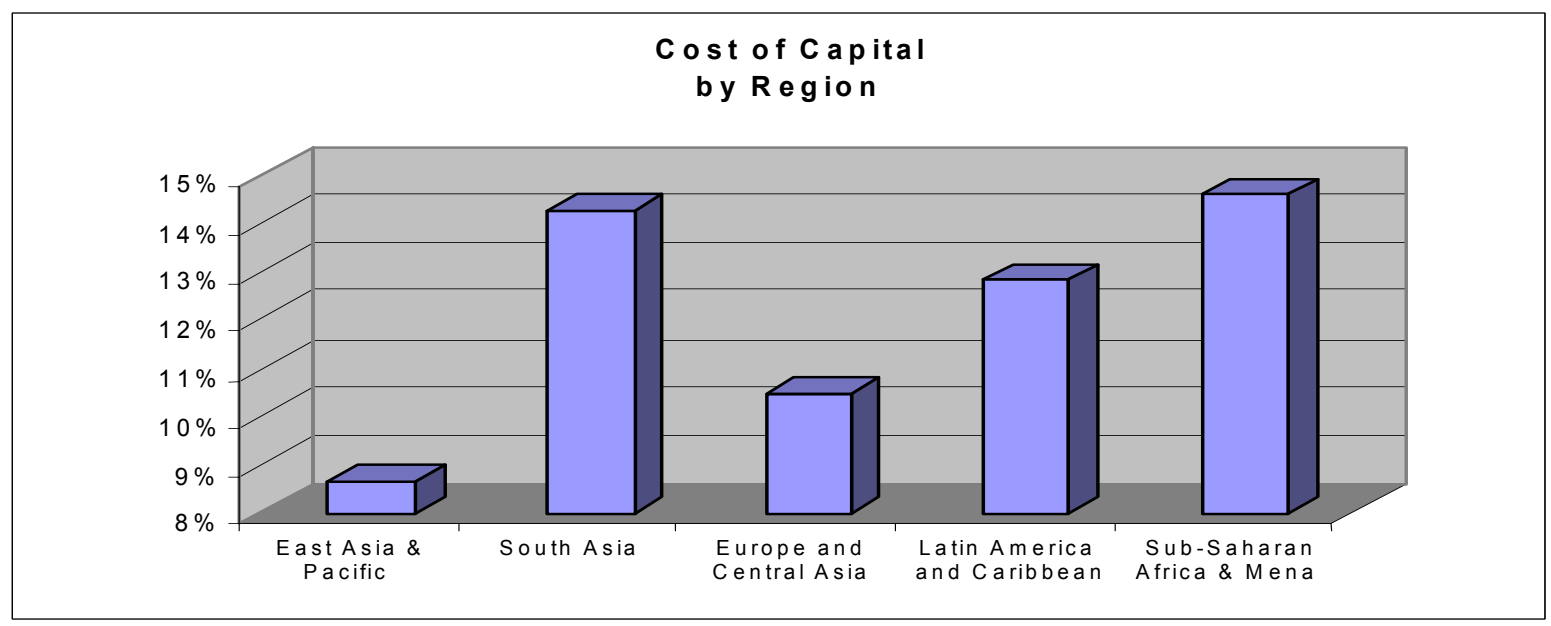

From a social viewpoint, these results are disturbing. Indeed, the cost of capital is the clearest indicators of what average tariff levels are expected to be. Hence, the comparison of cost of capital across regions or income groups gives a sense of the expected differences in averages tariffs across these regions and income groups. These results suggest that the poorer the country, the higher the risk, and hence the higher the cost of capital which, in turn, implies that the poorer the country, the higher the average tariff (all other things, including technology, being equal).

From the database collected, the last thing that can be done with respect to the cost of capital is to present sector specific estimates of this cost in the various country groupings. The size of the sample does, however, not allow a presentation of the results for the various geographical regions. These results for the various sectors are summarized in Figure 4. It generally confirms the earlier results. In addition, it shows that expected return on capital varied the most for the energy and water sectors between 1998 and 2002. Indeed, it varied between $10.7 \%$, for both sector in upper-middle income level countries, to $15.1 \%$ for water and $15.6 \%$ for energy in low-income level countries. The differences were lower for the transport infrastructures. Indeed, for ports it varied from $11.4 \%$ to $14.4 \%$ while for railways it 
varied from $11.6 \%$ o $13.7 \%$. The railways sector is somewhat unusual in that low middle income countries show the highest cost of capital.

Figure 4: Estimated weighted average cost of capital by sector according to income levels (1998-2002)

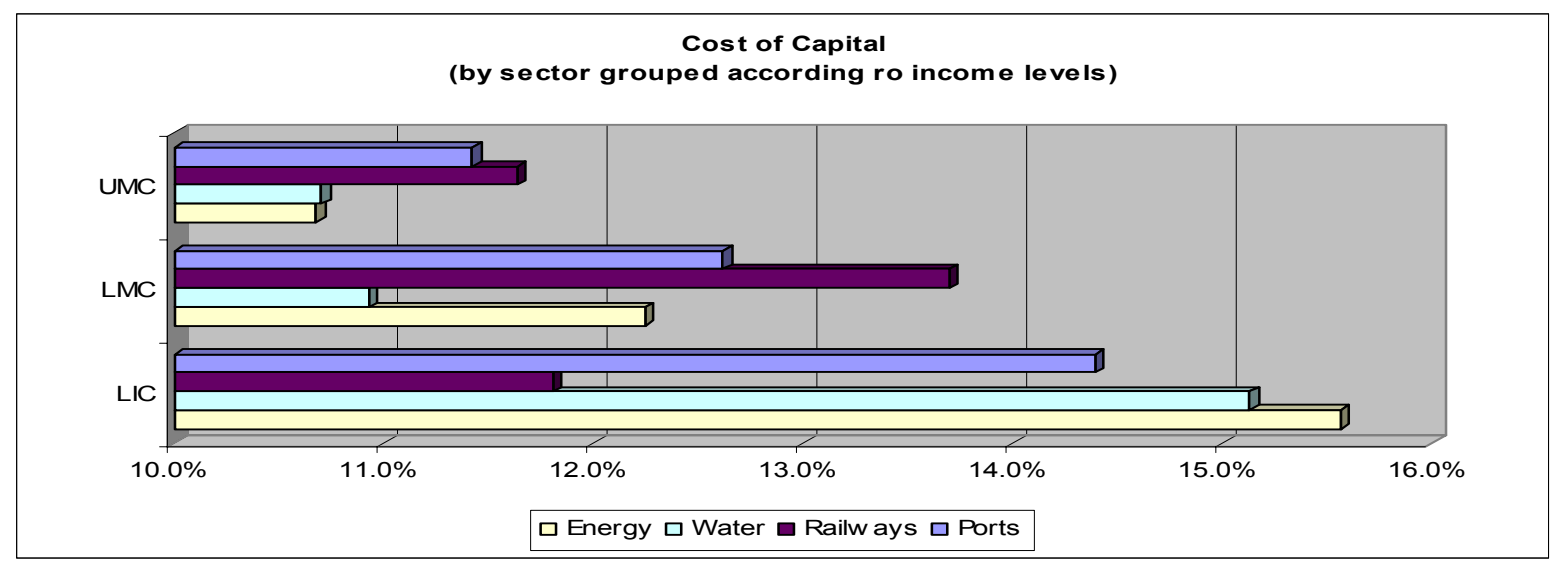

It may be useful to point out that even if the cost of capital levels seems to be fairly high by comparison to the costs of capital observed in similar industries in OECD countries, these numbers benefit from the high leverage of the companies noted earlier which maintains the relative importance of the cost of equity low in comparison to the cost of debt. Indeed, the average cost of equity estimated for the sample $(19.2 \%, 14.5 \%$ and $13.8 \%$ respectively for LIC, LMC and UMC), is significantly larger than the cost of capital $(15.4 \%, 11.8 \%$ and $11 \%$, respectively). Figure 5 summarizes the estimates of the cost of equity across sectors for the three main income groups. The cross sectoral differences observed for the cost of capital are however confirmed with the highest cost of equity for all sectors, except railways, higher than $19 \%$ and above $22 \%$ for ports in LICs.

Figure 5: Average Cost of equity by sector (1998-2002)

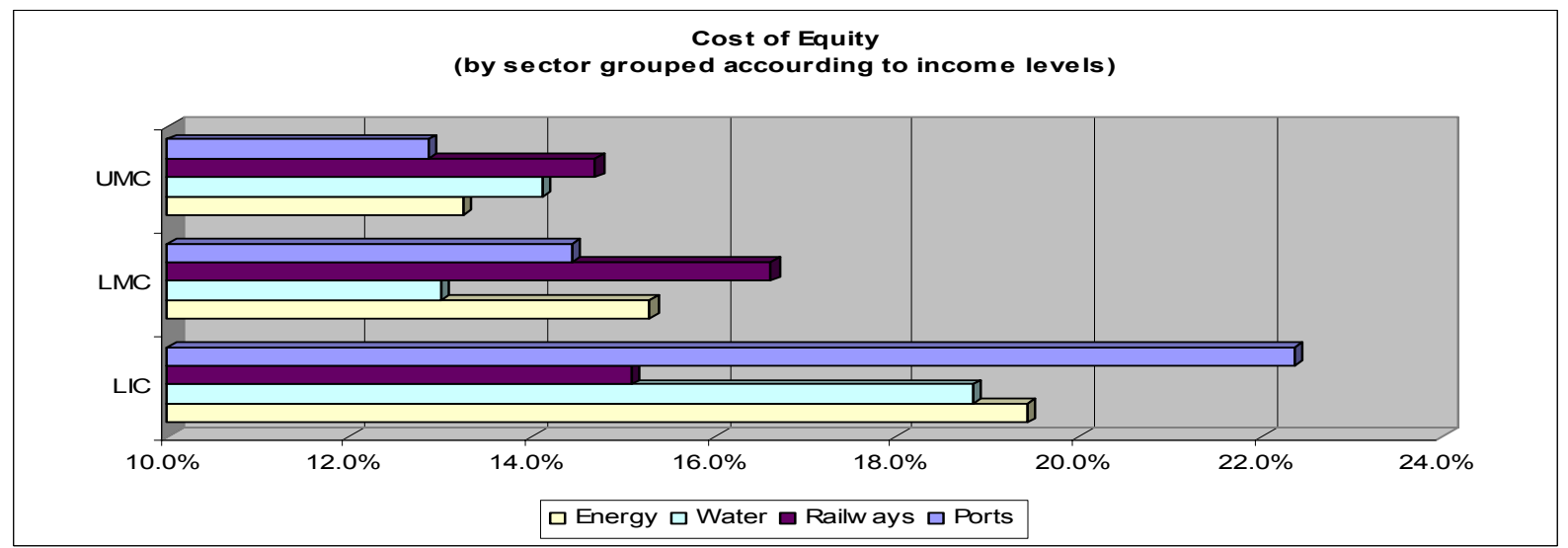




\section{Are returns consistent with risks?}

The relatively high costs of capital presented in section 4 would not have been a major issue if the associated returns had been at matching levels. The fact is, however, that private investment in infrastructure declined significantly during the 5 years that followed the Asian crisis. This implies that returns have probably not been consistent with the high levels of the cost of capital across regions. This would be relatively easy to demonstrate if estimates of the internal rate of return (IRR) for these projects were available for the companies in this sample. Indeed, the IRR summarizes in one single number both, the return earned by shareholders up to date and the return over the entire life of the project (when the residual value at the end of the project is taken into account). The data is however not available. ${ }^{14}$

To get a sense of the (mis-)match between risks and return, we rely on a comparison of the cost of equity (one of the components of the cost of capital) and of the returns on equity $(\mathrm{RoE}){ }^{15} \mathrm{We}$ present the results per sector, per region and per income level groupings, respectively.

Starting with the estimates of the average returns per sector, Figure 6 shows that the RoE varied considerably across sectors but were lower than costs of equity in every case in the 5 years that followed the Asian crisis. The water and railroad sectors had negative average returns of $-0.14 \%$ and $-6.7 \%$ respectively, while the port and energy sectors had positive returns of $6-8 \%$. The main point of Figure 6 however is that none of the sectors managed to generate a RoE consistent with the cost of equity. In other words, for no sectors were returns consistent with the risk assessed in the post crisis years.

Figure 6: Average returns by sectors (1998-2002)

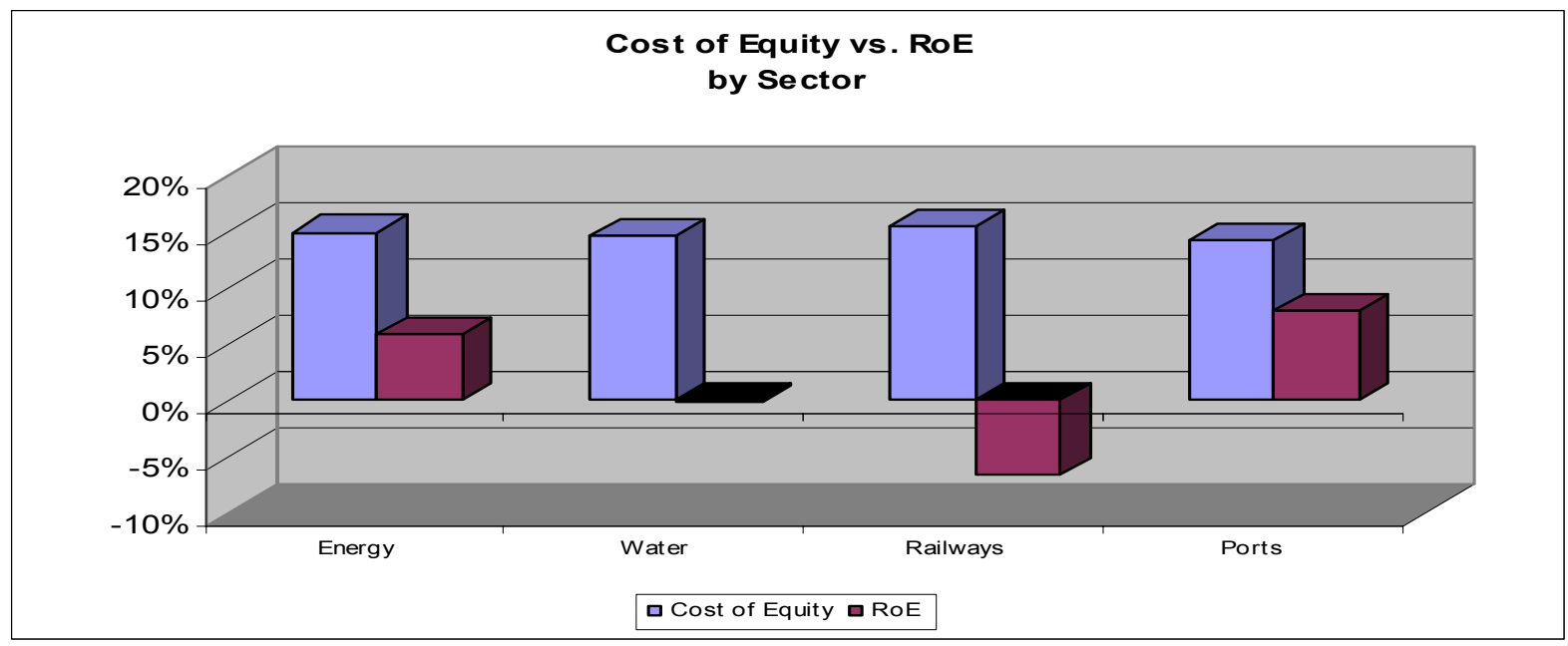

\footnotetext{
${ }^{14}$ The interested reader could refer to Sirtaine et al (2004) who were able to collect the necessary data for a sample of Latin American infrastructure companies.

${ }^{15}$ Contrary to the IRR, the RoE is exclusively an annual measure and missed out on the dynamic dimension of infrastructure projects, include the life cycle dimensions discussed earlier. The data is however not available for the sample.
} 
To complement the figure, it is useful to point out that the two worst performing sectors in terms of RoE, water and railways, are also those which showed the highest level of volatility as indicated by standard deviations of RoE of respectively 0.23 ad 0.17 . $^{16}$ These relatively high levels of volatility reflect the wide diversity of experiences covered by the sample. For ports and electricity, it is only 0.9 which is surprisingly low for such a diversified sample.

Figure 7 is intended to reveal any possible difference across regions on the gloom scenario emerging from the sectoral picture. The story is probably only robust for East Asia and Latin America where the number of countries covered by the sample is large enough (30 and 55 respectively) generating an average RoE of about $11 \%$ for East Asia and $-0.8 \%$ for Latin America between 1998 and 2002. The negative returns in Latin America are consistent with the slow down observed in private investment in the region. However, East Asia was the only on region in which risk and returns were a match! The result for East Asia is in fact quite robust since the standard deviation around the mean is only 0.05. The Latin American experience showed much more volatility with a standard deviation of 0.19 around the mean. ${ }^{17}$ The other results (RoE of almost $12 \%$ for South Asia, 3.7\% for Eastern Europe and $0.6 \%$ for Africa) are however in general interesting to report because they suggest company returns varied significantly across regions and not just between East Asia and Latin America. In South Asia and Eastern Europe, the volatility of these RoE was small (0.07 and 0.09 respectively), while it was quite large in Africa (0.18).

Figure 7: Average returns by region (1998-2002)

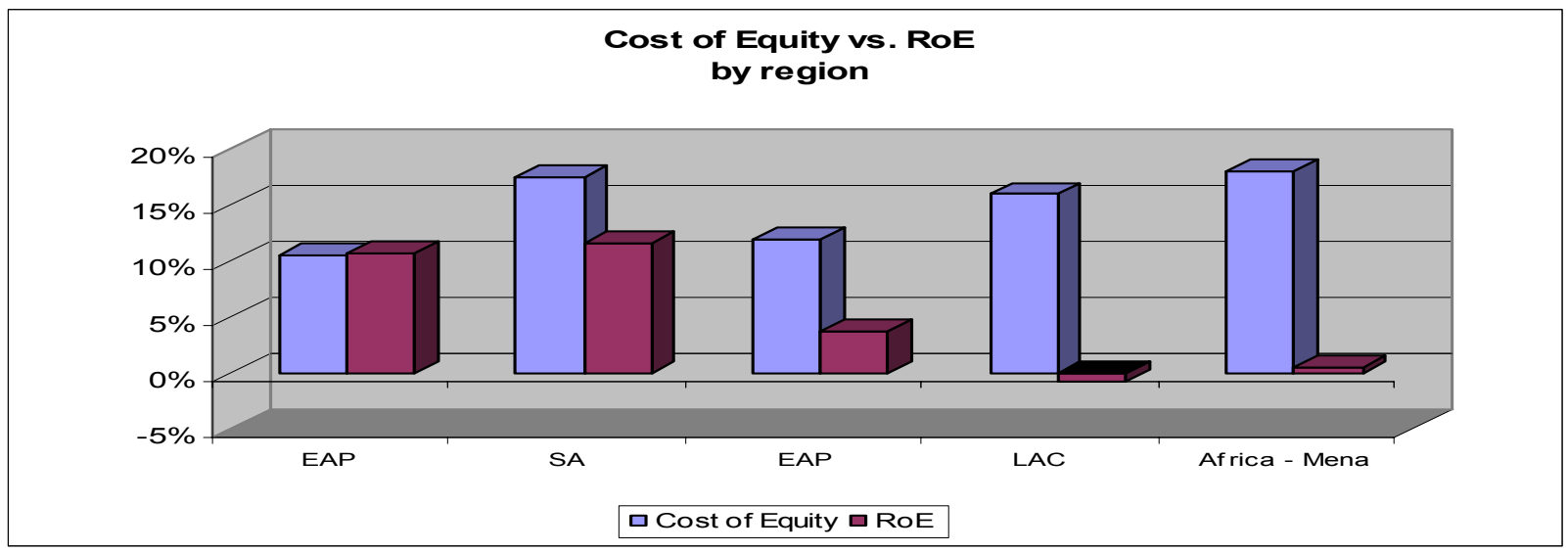

\footnotetext{
${ }^{16}$ Volatility is defined here as the grade of dispersion of the expected return in the sample and is usually measured as the annualized standard deviation. The standard deviation is a weighted average of the deviations from the expected value and it provides an idea of how far above or below the expected value the actual value is likely to be.

${ }^{17}$ The differences in volatility between the two regions also reflects differences in approached to attract private investment. In East Asia, project finance approaches dominated, forcing well targeted ring fencing of risks at the project levels within sectors, while in Latin America, the dominating approach was the concessioning of services which were often quite encompassing at the sectoral level.
} 
To get more robust results, it is useful to look at the aggregation of RoE per categories of countries classified according their income levels where sample sizes are large enough. This is done in Figure 8 which shows that none of the country groups reached their corresponding hurdle rates. However, it can be seen that low-income countries, which have a riskier (i.e.: higher) hurdle rate have had, on average, quite low returns (5.1\%). It is surprising though, that returns in upper-middle income countries $(1.1 \%)$ have been lower than in lowincome countries $(5.1 \%)$. However, low-middle income countries have, on average, the highest returns (7.6\%), which is still below the global developing countries's hurdle rate(around 14\%) - i.e. the one calculated for the whole sample. As a result, investors in lowmiddle income level countries, where the RoE relative to their respective hurdle rates is relatively low, experienced the least significant losses between 1998 and 2002. This conclusion is strengthened by the analysis of the volatility of returns across income groups. This analysis shows that the LMIC also enjoyed the lowest standard deviation (0.06) among the three groups. In fact, LIC and UMIC saw relatively strong volatility in their returns with standard deviations of 0.15 and 0.17 respectively.

Figure 8 Average profitability per countries according to Income Levels(1998-2002)

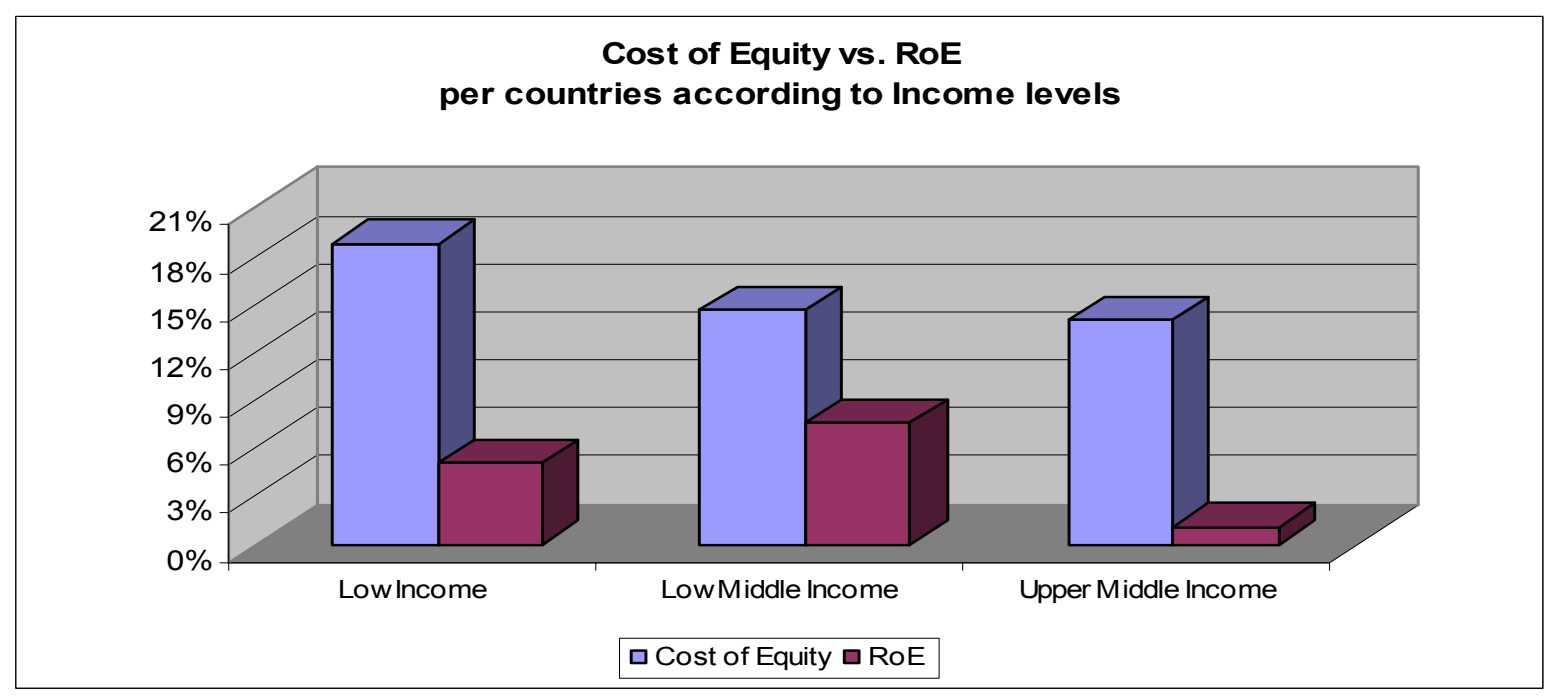

In sum, the analysis of the match between risk and returns and the stability of the returns contributes to explain the major slow down in capital flows relatively well for most regions and all income groups. The only exception may be Africa where the huge wedge between return on equity and cost of equity is reflected in the low absolute levels of investment but not in the somewhat unexpected increase in the flows of investments observed over the last three years. ${ }^{18}$ Overall, only 32 of the 120 companies covered by this sample enjoyed an RoE larger than their CoE during the post Asia crisis period, implying that two thirds had bad experiences and would probably be reluctant to disburse or even commit significant new investments. This is particularly true for the rail and water sectors since thye represented only $25 \%$ the successful companies. The rest were in energy and ports.

\footnotetext{
${ }^{18}$ World Bank (2003), PPI database
} 


\section{Are things improving since the beginning of the crisis?}

Now that the average mismatch between returns and risks has been established quantitatively, the remaining fact to document is the extent to which things have improved since the East Asia crisis. To do so we report the evolution of the $\mathrm{CoE}$ and the RoE on an annual basis between 1998 and 2002. Figure 9 does it for the infrastructure sector as a whole for the full set of countries as well as for each region. Figure 10 does it for each sector.

Our sample suggests that while returns on equity varied considerably across regions with a downward trend, the costs of equity has generally been essentially flat during the period. For the full sample, the gap between return and cost of equity has in fact increased suggesting that on average the prospects for private sector participation did not improve for the sector. In fact, they deteriorated between 1998 and 2002.

At the regional level, the only region with a clear positive story is East Asia where the gap between returns and costs has shrunk and has been almost eliminated by the end of 2002 . South Asia and Eastern Europe is not too far behind but the volatility of the returns over time has continued to be a problem in both regions. For Africa and Latin America, the wedge between returns and the cost of equity has increased over time. Interestingly enough the two poorest regions, Africa and South Asia, were the only two to show a positive net return on equity at the beginning of the period but both loose that advantage over time, Africa much faster and dramatically than South Asia.

At this level of aggregation, the results are somewhat surprising for all regions but East Asia. The expectation was that regions would eventually recover everywhere but that expectation had not been met as of end of 2002. Every region seems to have its own dynamics, which adds to the bad reputation that the sector gained when many of the deals which had been signed in East Asia fell apart with the crisis. In South Asia, a number of sour deals in energy in India and Pakistan as well as a number of never closed high profile deals in all countries of the region may are maintaining the equity costs high. In Eastern Europe, a series of crisis in Russia and failed deals in a number of other countries of the region (toll roads and/or rail and water in Hungary, Poland, Ukraine,...) have contributed to the volatility over time of returns independently of the East Asia crisis. In Africa, frustration with high transaction costs have maintained cost high and the declining ability to generate cash from basic public services in many countries have contributed to a deterioration of equity returns. As for Latin America, the financial performance of the sector simply echoes the major financial crisis that it some of the largest actors in the infrastructure reform experience. It could be argued that in Brazil the Asian crisis had a dramatic effect since it hit many of the energy and toll roads deals that were about or had just been signed in the country. The slow adjustment of Brazil then had macroeconomic effects in Argentina where additional internal fiscal problems fueled the crisis that culminated in January 2002. Bolivia and Peru, the other two major countries with a large number of PPI deals saw their own versions of the macroeconomic crisis. In all countries, operators were hit on the cost side as well as on the return side through a rapidly shrinking demand stemming from rapidly rising levels of unemployment. 
Figure 9: Annual equity returns vs. costs in infrastructure in LDCs per region
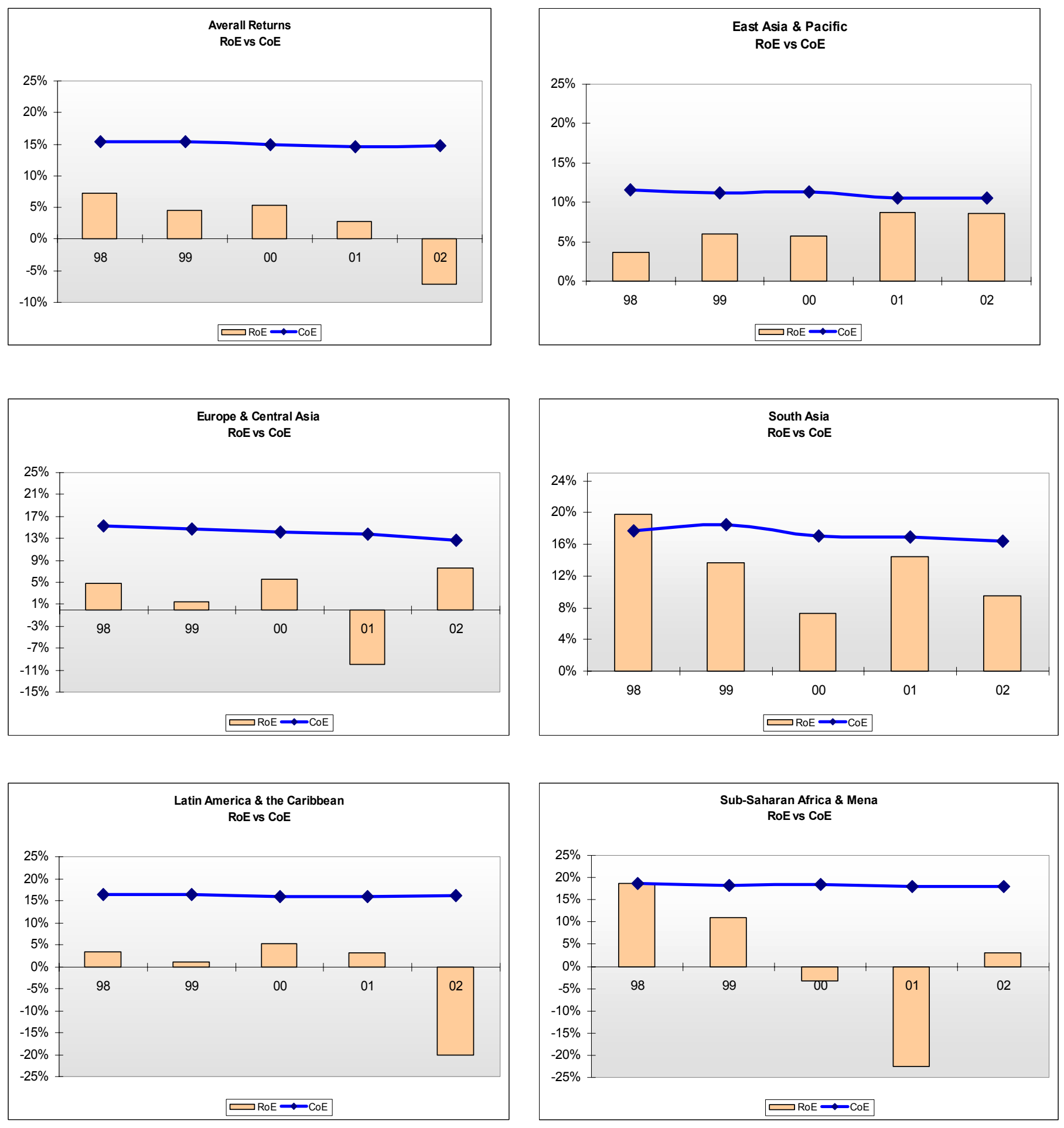
In terms of income groups, the emerging story is much clearer as seen in Figure 10. In a nutshell, LMIC are been doing quite well since the crisis except maybe in 2002 where the Argentina crisis had ripple effects in a large number of countries, in particular in Latin America. The UMIC, which include many of the Latin American countries with private sector operators of infrastructure services have been doing quite poorly since the Asian crisis. The LIC have also been doing poorly although they seem to have seen their situation get worse later than the other regions. In fact, they seem to have lagged reaction to all international crisis since in 2002 they did relatively well in comparison to higher income countries.

Figure 10: Annual equity returns vs. costs in infrastructure in LDCs per income groups
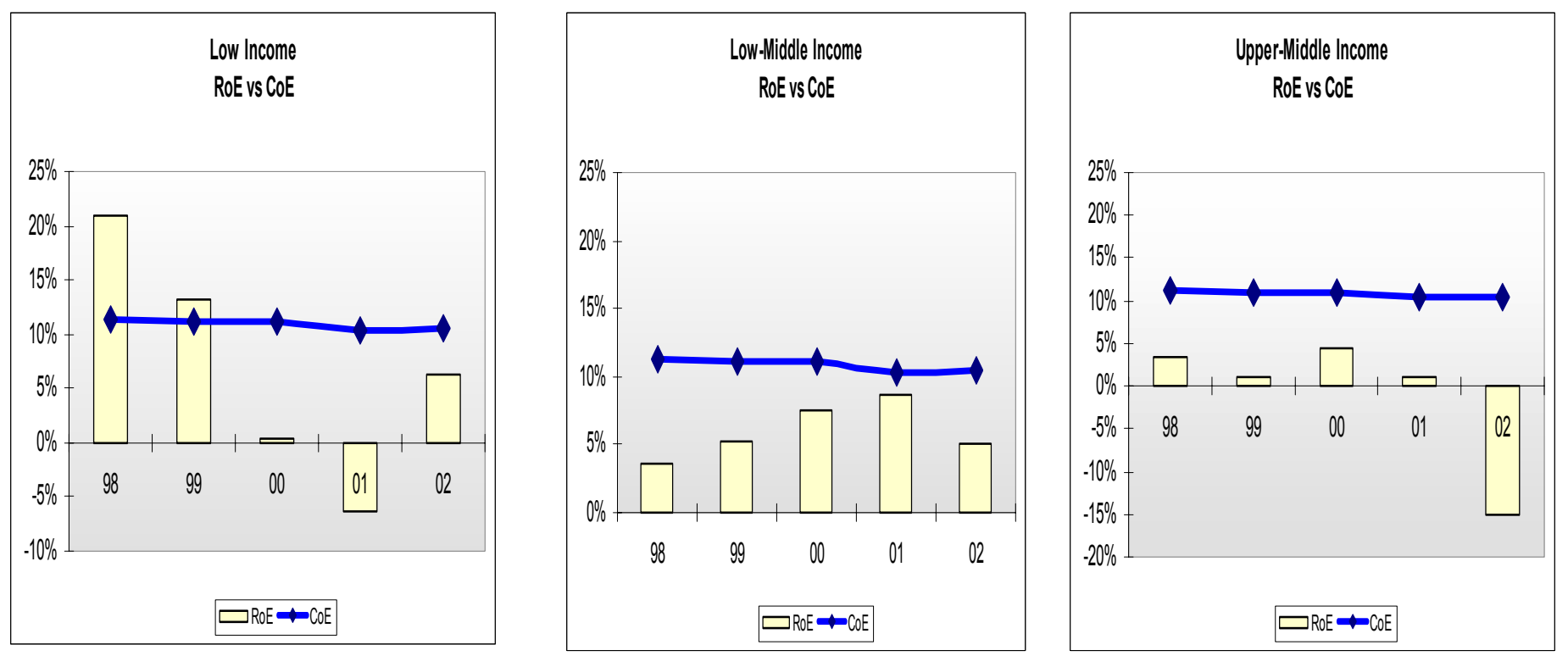

As for the emerging sectoral story, Figure 11 shows the major insights. The first observation is that in none of the sectors have the returns been high enough to cover the cost of equity throughout the period. Moreover, while the cost of equity has remained relatively stable, the returns on equity have evolved quite differently across sectors. Return have been following a declining trend in water and railways. They have in fact been negative every single year for railways throughout the period. The energy and the ports sector have been relatively well off in comparison.

To put things in perspective, it is useful to point out that both the water sectors and the railways sectors required very significant capital investments, that were heavily financed in foreign currency by external supporting agencies such as banks, international corporations or private investments. As a consequence, they were much more dramatically hit by the crisis, not only in East Asia but also in other parts of the developing world. Consider the fact that water operators were forced to pull out of their deals in developing countries. Energy operators, such as Enron, Hydroquebec and AES for instance have ended pulling out as well .

Figure 11 

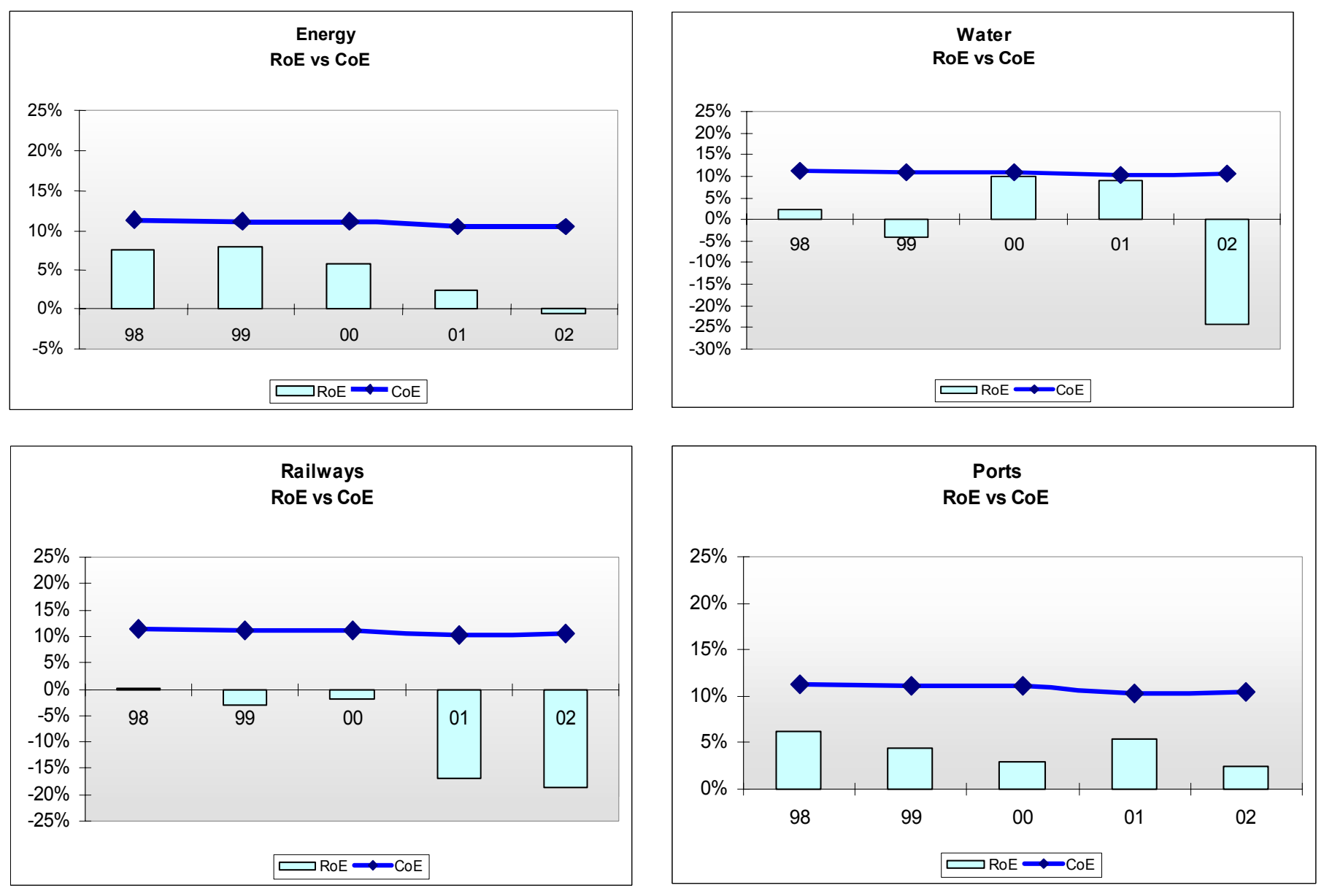

\section{Conclusion}

During 1998-2002 overall shareholder returns in our sample were insufficient relative to the risks taken. Thus most infrastructure companies are not particularly attractive investment opportunities - though there are notable caveats to this conclusion. Moreover, water and railway investments did worse than port and energy investments.

Investors in East Asia and the Pacific, South Asia, and to a lesser extent Europe and Central Asia did better than those in Latin America and Africa and the Middle East. And because the former regions are less risky, they have greater potential to become more attractive to investors. In addition, lower-middle-income countries appear to have a brighter investment outlook than low-income and upper-middle-income countries.

The main question to emerge from this analysis may thus be: If things are that bad, why are companies not pulling out? A first answer has to do with the life cycle view of the projects. These results provide a snapshot of a few bad years but many investors have a 
longer-term perspective reflected in their assessment of the IRR. The poor financial performance may be bad enough to slow down new projects, but not yet bad enough, at least in general, to motivate a pull out.

A second answer has to do with the creative accounting games that seem to characterize the sector. A foreign company declaring losses in a host country can distribute dividends on the same deal at headquarters. This is not contradictory at all; it simply reflects the weakness of international accounting standards and guidelines. In infrastructure, one of the most unusual characteristics of accounting rules relates to management fees. Current practice in developing countries allows the payment by a local concessionaire managed by a foreign company to be deducted as a cost locally but this payment is credited as income at the headquarters of the foreign company. This is not very different from what transfer pricing does for competitive companies. From the viewpoint of a regulated company, however, the implication is that the foreign company ends up having a guaranteed minimum return on equity, which in the host country is reflected in the revenue requirements used to assess the tariff level needed to cover the cost of capital, but is ignored in the revenue sources of the operator. In the other words, the investors make money twice on this specific component of the deal.

Thus, the main question emerging points to a fairly simple but crucial policy message: accounting transparency matters to the users but it drives the average tariff! This conclusion for the infrastructure sectors is, as expected, not very different from the conclusion obtained from analysis covering a wider set of sectors. For instance, there is quite a bit of evidence that more transparent accounting standards are associated with lower costs of capital in general and across countries. Indeed, this has been documented in the debate on the importance of closure rules (see for instance, Botosan (1997), Hail (2002) or Hail and Leuz (2003). It has also been documented in the context of assessments of the impact of corruption on the costs of borrowing for developing countries (Ciocchini, Durbin and Ng (2002)).

To conclude, it is probably fair to argue that this paper can only claim to be a first cut at processing the new information collected. While the benchmarks provided for the various key financial variables of the sector may be useful, much more work is needed, in particular more analytical work documenting the relationship between investment flows and financial costs and returns. Many other variables, including institutional and governance variables, need to be taken into account (as done by Hail and Luez (2004), for instance). In many ways, this additional analysis is needed not only to test the robustness of the sometimes surprising evidence presented in this paper but also to raise many more questions on the actual relevance of all these additional variables to achieve effective public partnerships in the interest of the infrastructure users in the poorest countries of the world. Indeed, while the potential and the need for a good public partnership in infrastructure continues to be strong, the evidence on its effectiveness continues to be mixed from a fiscal and a social viewpoint, revealing the knowledge gap we still need to address. 


\section{References}

Alexander, I. (forthcoming), Computing the Cost of Capital in for Regulated Infrastructure Services: A Manual, World Bank Institute, Studies in Development

Alexander, I., Estache A., and Oliveri A. (2001) 'A few things transport regulators should know about risk and the cost of capital', Utilities Policy, Volume: 9, Issue 1.

Botosan, C. (1997), "Disclosure level and the cost of equity capital", The Accounting Review, 72, 323-349

Ciocchini, F., E. Durbin and D. Ng (2002), Does Corruption Increase Emerging Market Bond Spreads ?, mimeo, forthcoming in the Journal of Economics and Business.

Hail, L and C. Leuz (2004), "International differences in the cost of equity capital: do legal institutions and securities institutions matter?", The Wharton Financial Institutions Center, Working Paper 04-06

Hail, L. (2002), The Impact of voluntary disclosures on the ex-ante cost of capital for Swiss firms", European Accounting Review, 11, 741-773

Leuz, C. and R. Verrechia (2000), "The economic consequences of increased disclosure", Journal of Accounting Research, 38, 91-124

Lintner, J. (1965). "The Valuation of Risk Assets and the Selection of Risky Investments in Stock Portfolios and Capital Budgets." Review of Economics and Statistics 47 (February): 13-37.

Sharpe, W. F. (1964), "Capital Asset Prices: A Theory of Market Equilibrium under Conditions of Risk." Journal of Finance 19 (September): 425-42.

Sharpe, W. F., and G. Cooper (1972), "Risk-return Classes of New York Stock Exchange Common Stocks, 1931-1967." Financial Analysts Journal 28 (March-April): 4654.

Sirtaine, S., M.E. Pinglo, V. Foster and J.L. Guasch (2004), "Latin America: On the returns earned by private infrastructure concessionaires", mimeo, The World Bank

The World Bank (2003), Private Participation in Infrastructure: Trends in Developing Countries in 1990-2001 


\section{Appendix :}

Table A1 Historical interest rates on US treasury bonds and Stocks S\&P

\begin{tabular}{|c|c|c|}
\hline & \multicolumn{2}{|c|}{ Annual Returns on Investments ir } \\
\hline Year & Stocks $(R m)$ & T.Bonds \\
\hline 1962 & $-9 \%$ & $6 \%$ \\
\hline 1963 & $23 \%$ & $2 \%$ \\
\hline 1964 & $16 \%$ & $4 \%$ \\
\hline 1965 & $12 \%$ & $1 \%$ \\
\hline 1966 & $-10 \%$ & $3 \%$ \\
\hline 1967 & $24 \%$ & $-2 \%$ \\
\hline 1968 & $11 \%$ & $3 \%$ \\
\hline 1969 & $-8 \%$ & $-5 \%$ \\
\hline 1970 & $4 \%$ & $17 \%$ \\
\hline 1971 & $14 \%$ & $10 \%$ \\
\hline 1972 & $19 \%$ & $3 \%$ \\
\hline 1973 & $-14 \%$ & $4 \%$ \\
\hline 1974 & $-26 \%$ & $2 \%$ \\
\hline 1975 & $37 \%$ & $4 \%$ \\
\hline 1976 & $24 \%$ & $16 \%$ \\
\hline 1977 & $-7 \%$ & $1 \%$ \\
\hline 1978 & $7 \%$ & $-1 \%$ \\
\hline 1979 & $19 \%$ & $1 \%$ \\
\hline 1980 & $32 \%$ & $-3 \%$ \\
\hline 1981 & $-5 \%$ & $8 \%$ \\
\hline 1982 & $20 \%$ & $33 \%$ \\
\hline 1983 & $22 \%$ & $3 \%$ \\
\hline 1984 & $6 \%$ & $14 \%$ \\
\hline 1985 & $31 \%$ & $26 \%$ \\
\hline 1986 & $18 \%$ & $24 \%$ \\
\hline 1987 & $6 \%$ & $-5 \%$ \\
\hline 1988 & $17 \%$ & $8 \%$ \\
\hline 1989 & $31 \%$ & $18 \%$ \\
\hline 1990 & $-3 \%$ & $6 \%$ \\
\hline 1991 & $30 \%$ & $15 \%$ \\
\hline 1992 & $7 \%$ & $9 \%$ \\
\hline 1993 & $10 \%$ & $14 \%$ \\
\hline 1994 & $1 \%$ & $-8 \%$ \\
\hline 1995 & $37 \%$ & $23 \%$ \\
\hline 1996 & $24 \%$ & $1 \%$ \\
\hline 1997 & $32 \%$ & $10 \%$ \\
\hline 1998 & $28 \%$ & $15 \%$ \\
\hline 1999 & $21 \%$ & $-8 \%$ \\
\hline 2000 & $-9 \%$ & $17 \%$ \\
\hline 2001 & $-12 \%$ & $6 \%$ \\
\hline 2002 & $-22 \%$ & $15 \%$ \\
\hline
\end{tabular}

Source: Bondsonline, interest rate on the US 3-month Treasury bond over a 40-year period 
$\underline{\text { Table A2: Nominal corporate income tax rates by country }}$

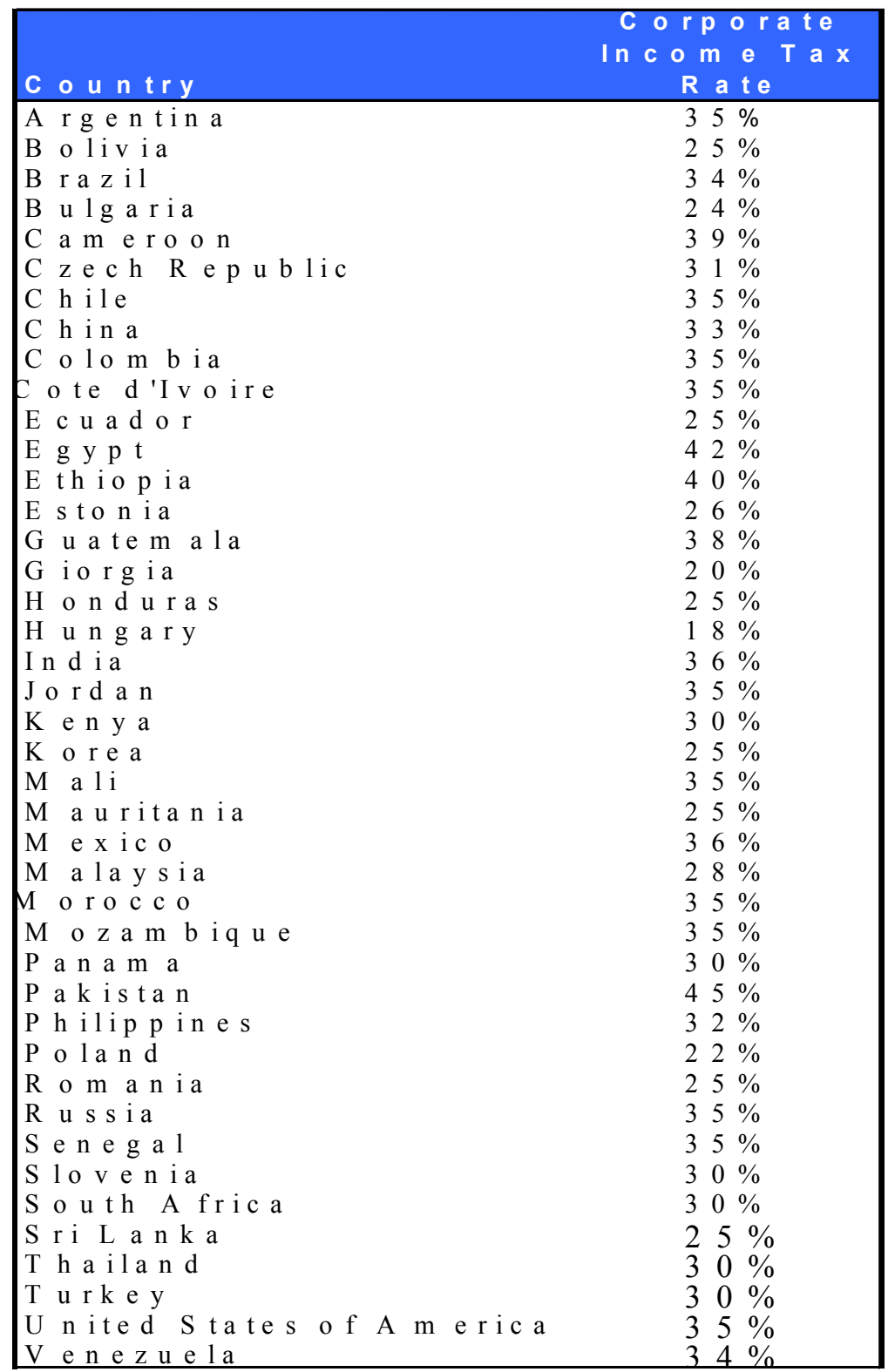

Source: Coopers-Lybrand-Price-Waterhouse 